\title{
Sleeping Pills and Quality of Wake Time: The Missing Link
}

Sohil A Khan ${ }^{1,2,8 *}$, Treasure M McGuire ${ }^{2-5}$ and Helen S Heussler ${ }^{2,6,7}$

${ }^{1}$ School of Pharmacy, Griffith University, Gold Coast, Australia

${ }^{2}$ Mater Research Institute, Mater Health Services, South Brisbane, Australia

${ }^{3}$ Mater Pharmacy Services, Mater Health Services, South Brisbane, Australia

${ }^{4}$ Faculty of Health Sciences and Medicine, Bond University, Gold Coast, Australia

${ }^{5}$ School of Pharmacy, The University of Queensland, Woolloongabba, Australia

${ }^{6}$ Deparrment of Respiratory and Sleep Medicine, Mater Children's Hospital, Mater Health Services, South Brisbane, Australia

${ }^{7}$ School of Medicine, The University of Queensland, Herston, Australia

${ }^{8}$ Griffith Health Institute, Griffith University, Gold Coast, Australia

\begin{abstract}
Background: The rising incidence of insomnia in a 24/7 global society quantifies the burden for the individual, in terms of reduced quality of life (QOL), and for society at large, in terms of work absenteeism, disability, and health care costs.
\end{abstract}

Aim: To evaluate research on hypnosedatives (benzodiazepines, non-benzodiazepines) and complementary medicines in paediatric insomnia where quality of wake time is one of the key efficacy outcomes.

Design and setting: Retrospective data analysis of clinical studies in paediatric insomnia

Methods: A systematic review of clinical studies of hypnosedatives and complementary medicines in paediatric insomnia was conducted. PubMed and Cochrane Central Register of Controlled Trials (January 2002- August 2013) were searched for studies in children aged 3 to18 years (male or female). Quality of wake time and/or health related QOL parameters were assessed as the outcomes.

Results: From 31 potentially relevant studies, only one, involving melatonin, met the inclusion criteria. One hundred and forty six children (aged 3 to 15 years 8 months) diagnosed with insomnia were evaluated in a 12 week double masked randomised placebo controlled phase III multi-centre trial. Child behaviour and family functioning showed some improvement and favoured use of melatonin but was not statistically significant. There were no controlled clinical studies evaluating the impact of benzodiazepines and non-benzodiazepines hypnosedatives on quality of wake time in the management of paediatric insomnia.

Conclusion: Data on quality of wake time in children with insomnia are scarce. Research has focused on addressing the metrics of sleep, with quality of wake time notably ignored. QOL measurement provides valuable information about the psychological and social impact of treatment on children with insomnia. Complementary medicines such as melatonin appear to improve the quality of wake time in paediatric insomnia where there are comorbid conditions; but further research is needed.

Keywords: Insomnia; Benzodiazepines; Non-benzodiazepines; Melatonin; Sleep; Children; Quality of life

\section{Introduction}

Human beings spend approximately one-third of their lifetime sleeping [1]. As one of the most fundamental processes of life, sleep has attracted a great deal of attention from ancient philosophers to present day biomedical researchers. The rising incidence of insomnia in a $24 / 7$ global society continues to create increasing demands that pose significant challenges to sleep research and circadian physiology. A recently published epidemiological study [2] quantifies the burden of chronic insomnia for the individual, in terms of reduced Quality of Life (QOL), and for society at large, in terms of work absenteeism, disability and health care costs. The incidence is surprisingly high in the paediatric population, with a quarter of all children experiencing sleep problems. In children with visual impairment and neurodevelopmental disorders, the incidence is as high as $80 \%$ [3]. It is likely that this also has an impact on the carers of the affected child.

A sleep disorder exists when a lower quality of sleep results in impaired functioning or excessive sleepiness. For the past four decades, prescription hypnosedatives (benzodiazepine or non-benzodiazepine) have been widely used in the management of sleep disorders in adults and children. However, the risk associated with their chronic use (dependence, increased abuse potential, withdrawal symptoms) is alarming [4]. Recently, complementary medicines such as melatonin and valerian have gathered interest in sleep medicine. Prescriptions for sleep problems are common with melatonin, clonidine and antihistamines amongst the most frequent in paediatric practice [5] There is significant variation in prescribing pharmacotherapeutic options in insomnia with lack of consensus based guidelines in diverse patient population. When novel hypnosedatives are developed, the focus tends to be on the statistically significant increase in total sleep time (marginal in minutes) during the night instead of the effects on the quality of wakefulness [1]. Pharmaceutical companies are focussed heavily on the metrics of sleep; and have neglected quality of wake time as a key measure of hypnosedatives efficacy, yet quality of wake

*Corresponding author: Sohil A Khan, School of Pharmacy, Griffith University, Gold Coast, Australia, Tel: +61 75552 7097; Fax: +61 75552 8804; E-mail: s.khan@griffith.edu.au

Received August 27, 2013; Accepted September 12, 2013; Published September 172013

Citation: Khan SA, McGuire TM, Heussler HS (2013) Sleeping Pills and Quality of Wake Time: The Missing Link. J Sleep Disorders Ther 2: 138, doi:10.4172/2167. 0277.1000138

Copyright: (C) 2013 Khan SA, et al. This is an open-access article distributed unde the terms of the Creative Commons Attribution License, which permits unrestricted use, distribution, and reproduction in any medium, provided the original author and source are credited. 
time is an integral domain in the definition of insomnia disorders in the Diagnostic and Statistical Manual of Mental Disorders, $5^{\text {th }}$ edition, described as "... causing clinically significant distress or impairment in social, occupational or other important areas of functioning” [6].

Poor sleep can exacerbate medical, psychiatric or developmental conditions; and insomnia has been a contributing factor in traffic and work-related accidents [2]. High risk patients, with underlying comorbidities such as anxiety, depression and chronic pain, are more prone to impaired daytime function. However, there are few studies involving currently marketed hypnosedatives that evaluate the extent of improvement (if any) in daytime functioning or the consequences of disrupted sleep. This is not surprising, as the cohort of primary insomniacs selected for clinical trials tend to be without co-morbid conditions. This differs significantly from the 'real world' scenario where people with multiple co-morbidities are more likely to suffer from, and be adversely affected by insomnia. This review aims to evaluate research on hypnosedatives (benzodiazepines, non-benzodiazepines) and complementary medicines (e.g. melatonin) in paediatric insomnia where quality of wake time is one of the key efficacy outcomes.

\section{Method}

This systematic literature review included clinical trials that evaluated quality of wake time in paediatric insomnia. Participants included were children aged 3 to 18 years (male or female) on hypnosedatives [benzodiazepines or non-benzodiazepines (zolpidem, zaliplon, zopiclone, eszopiclone)] or complementary medicine for the management of insomnia. Both typically developing children with no co-morbidities and those with existing co-morbidities were included. PubMed and the Cochrane Central Register of Controlled Trials (January 2002 to August 2013) were searched using the following Medical Subject Heading [MeSH] terms: 'quality of life' AND [exp] 'child' AND 'sleep initiation and maintenance disorders'. Studies were then filtered to retrieve any involving a pharmacotherapeutic intervention - benzodiazepine, non-benzodiazepine or complementary hypnosedatives. The following string of terms was used: 'hypnotics and sedatives' OR [exp] 'plants' OR 'homeopathy' OR 'naturopathy' OR [exp] 'phytotherapy' OR [exp] 'medicine, traditional' OR 'horticultural therapy' OR 'melatonin' OR 'drugs chinese herbal OR 'plant extracts' OR 'complementary' (mp) OR 'herb' (mp). Only studies published in English language were included. An extended search (hand search) technique was applied to retrieve any relevant cross-references (Table $1)$.

\section{Results}

Of 31 potentially relevant studies retrieved, 26 were excluded as cohorts included adults or insomnia was not the primary diagnosis. The remaining five were selected for detailed evaluation. Four studies were excluded as they lacked a pharmacotherapeutic intervention, leaving one study for inclusion in this systematic review (Figure 1).

A recently published, randomised controlled trial [11] of the complementary medicine - melatonin was included for evaluation in the systematic review. This trial assessed the effectiveness and safety of melatonin in treating severe sleep problems in children with neurodevelopmental disorders. One hundred and forty-six children (aged 3 to 15 years and 8 months) were studied in a double masked randomised placebo controlled phase III multi-centre trial in 19 hospitals across England and Wales. Immediate release melatonin or matching placebo capsules were administered 45 minutes before the child's bedtime for a 12 week period. All children started with a $0.5 \mathrm{mg}$ capsule in a dose escalation design to $2 \mathrm{mg}, 6 \mathrm{mg}$, and $12 \mathrm{mg}$ depending on their response to treatment. Total sleep time comprised the primary outcome. Secondary outcomes included sleep onset latency, assessments of child behaviour, family functioning, and adverse events. Sleep was measured with diaries and actigraphy. Melatonin increased total sleep time by 22.4 minutes ( $95 \%$ confidence interval 0.5 to 44.3 minutes) measured by sleep diaries $(\mathrm{n}=110)$ and $13.3(-15.5$ to 42.2$)$ measured by actigraphy $(\mathrm{n}=59)$.

Quality of wake time was evaluated as a secondary outcome. Child behaviour and family functioning showed some improvement and favoured use of melatonin. Four questionnaires were administered: the Composite Sleep Disturbance Index (CSDI), Aberrant Behaviour Checklist $(\mathrm{ABC})$ to assess behavioural problems, the family impact module of the Paediatric Quality of Life inventory (PedsQL) to assess the quality of life of the care giver; and the Epworth Sleepiness Scale (ESS) to assess the daytime sleepiness of the care giver. The ESS scale showed a clinically small but statistically significant improvement of 1.6 points on the 24 point scale for melatonin compared with placebo. The results of the PedsQL and ABC tended to favour melatonin but were not statistically significant.

A summary of the commonly used tools to evaluate QOL in

\begin{tabular}{|c|c|c|c|c|c|c|c|c|}
\hline Study & $\mathbf{N}$ & $\begin{array}{l}\text { Age (yrs) } \\
\text { Mean }\end{array}$ & Objective & Study design & $\begin{array}{l}\text { Medical co- } \\
\text { morbidity }\end{array}$ & $\begin{array}{l}\text { Type of sleep } \\
\text { disorder }\end{array}$ & HRQOL tool & Study outcome \\
\hline $\begin{array}{l}\text { de Serres } \\
\text { et al. } \\
(2002)[7]\end{array}$ & 101 & 6.2 & $\begin{array}{c}\text { Impact of } \\
\text { adenotonsillectomy on } \\
\text { HRQOL in children with } \\
\text { OSDs }\end{array}$ & $\begin{array}{c}\text { Prospective } \\
\text { observational study }\end{array}$ & OSD & $\begin{array}{l}\text { OSD with } \\
\text { restless sleep }\end{array}$ & $\begin{array}{c}\text { Obstructive Sleep } \\
\text { Disorders-6 survey } \\
\text { (OSD-6) }\end{array}$ & $\begin{array}{l}\text { Sleep disorder - an } \\
\text { important domain that } \\
\text { directly affects } \mathrm{QOL}\end{array}$ \\
\hline $\begin{array}{l}\text { Rosen et } \\
\text { al. }(2002) \\
\quad[8]\end{array}$ & 298 & 11.1 & $\begin{array}{l}\text { Extent of SDB with } \\
\text { impairment of HRQOL }\end{array}$ & $\begin{array}{l}\text { Longitudinal genetic- } \\
\text { epidemiologic cohort } \\
\text { study }\end{array}$ & Obesity, Asthma & SDB & $\begin{array}{c}\text { Child Health } \\
\text { Questionnaire (CHQ- } \\
\text { PF50) }\end{array}$ & $\begin{array}{l}\text { Decrements in HRQOL } \\
\text { were measurable } \\
\text { even with mild SDB; } \\
\text { Increasing effects with } \\
\text { more severe SDB }\end{array}$ \\
\hline $\begin{array}{l}\text { Hart et al. } \\
(2005)[9]\end{array}$ & 80 & 11.2 & $\begin{array}{c}\text { Assess relationship } \\
\text { between sleep disturbance } \\
\text { and HRQOL }\end{array}$ & $\begin{array}{l}\text { Retrospective review } \\
\text { of a clinical database }\end{array}$ & $\begin{array}{l}\text { Obesity, pulmonary } \\
\text { and neurologic } \\
\text { disorders }\end{array}$ & $\begin{array}{c}\text { Behaviour and } \\
\text { biological origin }\end{array}$ & $\begin{array}{c}\text { Child Health } \\
\text { Questionnaire (CHQ- } \\
\text { PF50) }\end{array}$ & $\begin{array}{c}\text { Variety of HRQOL } \\
\text { decrements experienced } \\
\text { that may benefit from } \\
\text { intervention }\end{array}$ \\
\hline $\begin{array}{l}\text { Díez- } \\
\text { Montiel et } \\
\text { al. (2006) } \\
{[10]}\end{array}$ & 101 & 4.1 & $\begin{array}{c}\text { Long term impact } \\
\text { of tonsillectomy/ } \\
\text { adenoidectomy in children } \\
\text { with OSA }\end{array}$ & $\begin{array}{l}\text { Prospective } \\
\text { controlled study }\end{array}$ & SDB, OSA & SDB, OSA & OSDs-6 survey & $\begin{array}{l}\text { Long term improvement } \\
\text { in HRQOL after surgery } \\
\text { in children with OSA }\end{array}$ \\
\hline
\end{tabular}

Key: OSD: Obstructive Sleep Disorders, SDB: Sleep disordered breathing ; OSA: Obstructive sleep apnoea

Table 1: Characteristics of excluded studies (after detailed evaluation). 


\begin{tabular}{|c|c|}
\hline $\begin{array}{l}\text { Relevant papers identified from } \\
\text { search of PubMed and Cochrane, } \\
\text { and hand search }(n=31)\end{array}$ & \multirow{2}{*}{$\begin{array}{l}\text { Ineligible studies }(\mathrm{n}=26) \\
\text { Excluded based on: } \\
\text { - Age range; } \\
\text { - Insomnia not the primary } \\
\text { diagnosis }\end{array}$} \\
\hline $\begin{array}{l}\text { Potentially eligible studies } \\
\text { evaluated }(n=5)\end{array}$ & \\
\hline & Excluded studies $(n=4)$ \\
\hline$\downarrow$ & Pharmacotherapeutic \\
\hline $\begin{array}{l}\text { Studies included in descriptive } \\
\text { analysis }(n=1)\end{array}$ & $\begin{array}{l}\text { intervention (i.e. } \\
\text { hypnosedatives) not } \\
\text { administered OR not reported }\end{array}$ \\
\hline
\end{tabular}

Figure 1: Flow chart of study selection process. The characteristics of the excluded studies (after detailed evaluation) are provided in Table 1. The participants' mean age was 8 years. These studies highlighted the impact of sleep problems on health related QOL (HRQOL) in children with various co-morbid conditions (not primary insomniacs).

insomnia and other sleep problems in children are presented in Table 2. It should be noted that administration of such tools in children less than 5 years needed to be completed by their parents/care givers.

\section{Discussion}

In recent times, measurement of QOL has added a new dimension to clinical trials and the drug development process. Results of epidemiological studies have demonstrated the increasing burden of chronic disease and its social impact, based on disability and not mortality. QOL measurement provides valuable information about the psychological and social impact of treatment on children, especially where differences in survival rates are anticipated. Despite the lack of a pharmacotherapeutic intervention in the four studies excluded from this systematic review, they serve to highlight the adverse impact of paediatric sleep disorders on HRQOL.

To the best of our knowledge, there is only one controlled trial that has evaluated the impact of a pharmacotherapeutic intervention on quality of wake time in paediatric insomnia. This study assessed the impact of melatonin on QOL and daytime functioning in children with neurodevelopmental disorders suffering from severe sleep problems [11]. Findings from measures of child behaviour and family QOL tended to favour melatonin but were not statistically significant. The authors justify this as the outcome measures were not sensitive enough over the study time period (12 weeks). The lack of studies addressing this issue with benzodiazepine or non-benzodiazepine hypnosedatives is surprising, considering their extensive use. Nonetheless, the melatonin study provides a baseline for future trials to focus on this neglected but an important parameter in sleep medicine - the quality of wake time.

A similar search in adult insomniacs with co-morbid conditions also retrieved only one placebo-controlled trial [18]. Claimed to be the first of its kind, the study demonstrated that long-term nightly treatment of primary insomnia with eszopiclone was able to enhance QOL, reduce work limitations, and reduce global insomnia severity, in addition to improving patient-reported sleep variables. Patientreported sleep and daytime function were improved more with the hypnosedative than with placebo at months 1-6 (duration: 6 months)
$(\mathrm{P}<0.001)$. Furthermore, statistically significant improvements were observed with eszopiclone compared with placebo for the SF-36 domains of Physical Functioning, Vitality, and Social Functioning $(\mathrm{P}<0.05)$, and all domains of the work limitations questionnaire $(\mathrm{P}<0.05)$. As this trial was conducted in primary insomniacs, impact of quality of wake time from the findings may not be extrapolated to patients with co-morbid conditions.

The use of medication to manage insomnia often follows a 'onesize-fits-all' approach. Yet the nature of the sleep problem experienced by those with insomnia varies. At present, daytime performance is considered as an absence of impairment - improvement of function with benzodiazepines or benzodiazepine receptor agonists has never been demonstrated. There are a number of barriers in evaluating quality of wake time. One is the lack of subjective and objective parameters to evaluate the clinical effect. Validated tools designed to assess HRQOL (Table 2) would be suitable for evaluating daytime performance and QOL in paediatric sleep pharmacotherapy.

Insomniacs with co-morbid conditions (e.g. neurodevelopmental disorders or circadian rhythm sleep disorders) are presented with challenging therapeutic decisions. A recently published therapeutic guideline [19] highlighted the need for studies to identify how to optimally manage insomnia in patients with co-morbid conditions. Newer strategies such as chronobiotic therapies are under trial. Melatonin seems one of the promising options to address this unexplored yet an important clinical domain of sleep medicine.

\section{Implications for practice and research}

- Despite their long history in the management of sleep disorders, there are no controlled clinical studies evaluating the impact of benzodiazepines and non-benzodiazepines hypnosedatives on quality of wake time in the management of paediatric insomnia.

- Complementary medicines such as melatonin appear to improve the quality of wake time in paediatric insomnia where there are co-morbid conditions (e.g. neurodevelopmental disorders, visual impairment and circadian rhythm sleep disorders). Further long term studies (more than 6 months) are needed. 
Citation: Khan SA, McGuire TM, Heussler HS (2013) Sleeping Pills and Quality of Wake Time: The Missing Link. J Sleep Disorders Ther 2: 138. doi:10.4172/2167-0277.1000138

Page 4 of 4

\begin{tabular}{|c|c|c|c|c|c|c|c|c|}
\hline Measure & $\begin{array}{l}\text { Age range } \\
\text { (years) }\end{array}$ & Concept & $\begin{array}{l}\text { Child (self) } \\
\text { Report }\end{array}$ & $\begin{array}{l}\text { Parent } \\
\text { (proxy) } \\
\text { Report }\end{array}$ & Domain & $\begin{array}{l}\text { Time to } \\
\text { complete } \\
\text { (min) }\end{array}$ & Reliability data & $\begin{array}{c}\text { Validity } \\
\text { data }\end{array}$ \\
\hline $\begin{array}{l}\text { Child Health and } \\
\text { Illness Profile [12] }\end{array}$ & $\begin{array}{l}\text { 6-11 and } \\
12-17\end{array}$ & $\begin{array}{c}\text { Measure based on a broad } \\
\text { concept that includes evaluation of } \\
\text { perception of well being and illness, } \\
\text { participation in developmentally } \\
\text { appropriate tasks, and activities } \\
\text { or behaviours that promote or } \\
\text { threaten health }\end{array}$ & $x$ & & $\begin{array}{c}6 \text { domain; Child } \\
\text { edition (6-11 } \\
\text { years); Adolescent } \\
\text { edition ( } 12-17 \\
\text { years) }\end{array}$ & 30 & $x$ & $x$ \\
\hline $\begin{array}{c}\text { Child Health } \\
\text { Questionnaire [13] }\end{array}$ & $5-18$ & $\begin{array}{c}\text { Measures health with regard to } \\
\text { physical, psychological and social } \\
\text { domains }\end{array}$ & $x$ & $x$ & $\begin{array}{l}11 \text { domains; Self } \\
\text { and } \\
\text { Parent version }\end{array}$ & 20 & $x$ & $x$ \\
\hline $\begin{array}{c}\text { Dartmouth Coop } \\
\text { Functional Health } \\
\text { Assessment Charts } \\
{[14]}\end{array}$ & 15 (median) & $\begin{array}{c}\text { Measures exclusive dimensions of } \\
\text { health and social problems through } \\
\text { picture/word charts }\end{array}$ & $x$ & & $\begin{array}{l}6 \text { charts (pictures } \\
\text { and words) }\end{array}$ & $15-20$ & $x$ & \\
\hline KINDL [15] & $4-16$ & $\begin{array}{l}\text { Describes physical, psychological, } \\
\text { social, and functional aspects of } \\
\text { well-being and functioning from } \\
\text { patient's perspective }\end{array}$ & $x$ & $x$ & 6 domains & 10 & $x$ & $x$ \\
\hline $\begin{array}{c}\text { Pediatric Quality of } \\
\text { Life Questionnaire } \\
{[16]}\end{array}$ & $2-18$ & $\begin{array}{l}\text { Evaluates physical, mental and } \\
\text { social health of children and } \\
\text { adolescents }\end{array}$ & $x$ & $x$ & 4 domain, 23 items & $5-10$ & $x$ & $x$ \\
\hline $\begin{array}{c}\text { Quality of Life } \\
\text { Profile - Adolescent } \\
\text { Version [16] }\end{array}$ & $14-20$ & $\begin{array}{c}\text { Evaluates physical, psychological } \\
\text { and spiritual parameters through } \\
\text { being, belonging and becoming } \\
\text { options }\end{array}$ & $x$ & & $\begin{array}{c}3 \text { domains, } 54 \\
\text { items }\end{array}$ & 40 & $x$ & \\
\hline $\begin{array}{l}\text { Warwick Child } \\
\text { Health and } \\
\text { Morbidity Profile } \\
{[17]}\end{array}$ & $0-5$ & $\begin{array}{l}\text { Evaluates general, acute, chronic } \\
\text { and functional health status and } \\
\text { QOL }\end{array}$ & $x$ & $x$ & 10 domains & 10 & $x$ & \\
\hline
\end{tabular}

Table 2: Summary of generic measures of health-related QOL used in paediatric sleep disorders

- Inclusion of quality of wake time as a secondary outcome in pharmacotherapeutic studies will be a key step in addressing this neglected but significant aspect of sleep medicine.

There are number of good quality validated tools (outcome measures) to study the quality of wake time for therapeutic trials in insomnia although some of these may not be suitable where children are affected by disability.

\section{References}

1. Wafford KA, Ebert B (2008) Emerging anti-insomnia drugs: tackling sleeplessness and the quality of wake time. Nat Rev Drug Discov 7: 530-540.

2. Morin C, Jarrin DC (2013) Epidemiology of insomnia: prevalence, course, risk factors, and public health burden. Sleep Medicine Clinics.

3. Khan S, Heussler H, McGuire T, Dakin C, Pache D, et al. (2011) Melatonin for non-respiratory sleep disorders in visually impaired children. Cochrane Database Syst Rev: CD008473.

4. Glass J, Lanctôt KL, Herrmann N, Sproule BA, Busto UE (2005) Sedative hypnotics in older people with insomnia: meta-analysis of risks and benefits. BMJ 331: 1169.

5. Heussler H, Chan P, Price AM, Waters K, Davey MJ, et al. (2013) Pharmacological and non-pharmacological management of sleep disturbance in children: an Australian Paediatric Research Network survey. Sleep Med 14: 189-194.

6. American Psychiatric Association (2013) Diagnostic and Statistical Manual of Mental Disorders (5thedn.). Arlington, VA: American Psychiatric Publishing: $5-25$.

7. De Serres LM, Derkay C, Sie K, Biavati M, Jones J, et al. (2002) Impact of adenotonsillectomy on quality of life in children with obstructive sleep disorders. Arch Otolaryngol Head Neck Surg 128: 489-496.

8. Rosen CL, Palermo TM, Larkin EK, Redline S (2002) Health-related quality of life and sleep-disordered breathing in children. Sleep 25: 657-666.

9. Hart CN, Palermo TM, Rosen CL (2005) Health-related quality of life among children presenting to a pediatric sleep disorders clinic. Behav Sleep Med 3 . 4-17.

10. Díez-Montiel A, de Diego JI, Prim MP, Martín-Martínez MA, Pérez-Fernández $\mathrm{E}$, et al. (2006) Quality of life after surgical treatment of children with obstructive sleep apnea: long-term results. International Journal of Pediatric Otorhinolaryngology 70: 1575-1579.

11. Gringras P, Gamble C, Jones AP, Wiggs L, Williamson PR, et al. (2012) Melatonin for sleep problems in children with neurodevelopmental disorders: randomised double masked placebo controlled trial. BMJ 345: e6664.

12. Child health and illness profile - a comprehensive assessment of health and functioning for children and adolescents.

13. Waters E, Salmon L, Wake M, Hesketh K, Wright M (2000) The Child Health Questionnaire in Australia: reliability, validity and population means. Aust N Z J Public Health 24: 207-210.

14. Dartmouth COOP functional health assessment charts: brief measures fo clinical practice (1995) Quality of life and pharmacoeconomics. In: Spilker B, editor Clinical Trials 2nd edition Philadelphia, PA: Lippincott-Raven Publishers, 161-168.

15. KINDL: Information. Available from http://kindl.org/english/information/.

16. The PedsQL: Measurement model for pediatric quality of life inventory.

17. Spencer NJ, Coe C (2000) Validation of the Warwick Child Health and Morbidity profile in routine child health surveillance. Child Care Health Dev 26: 323-336.

18. Walsh JK, Krystal AD, Amato DA, Rubens R, Caron J, et al. (2007) Nightly treatment of primary insomnia with eszopiclone for six months: effect on sleep, quality of life, and work limitations. Sleep 30: 959-968.

19. Minkel J, Krystal AD (2013) Optimizing the Pharmacologic Treatment of Insomnia: Current Status and Future Horizons. Sleep Med Clin 8: 333-350.

Citation: Khan SA, McGuire TM, Heussler HS (2013) Sleeping Pills and Quality of Wake Time: The Missing Link. J Sleep Disorders Ther 2: 138. doi:10.4172/2167-0277.1000138 